\title{
High-Risk Adult Wilms' Tumour in Pregnancy: A Case Report
}

\author{
Stephen Kasenda ${ }^{1 *}$,DonnieMategula ${ }^{3}$, NoelChiphangwi $^{2}$, \\ Luis Aaron Gadama, ${ }^{4,5}$, Leo Peter Lockie Masamba ${ }^{2}$, \\ 1. Blantyre District Health Office, Blantyre, Malawi \\ 2. Department of Medicine, Queen Elizabeth Central Hospital, Blantyre, Malawi \\ 3. Malawi-Liverpool-Wellcome Trust Clinical Research Programme, Blantyre, Malawi \\ 4. Department of Obstetrics and Gynaecology Department, University of Malawi College of Medicine, Blantyre, \\ Malawi \\ 5. Department of Obstetrics and Gynaecology, Queen Elizabeth Central Hospital, Blantyre, Malawi
}

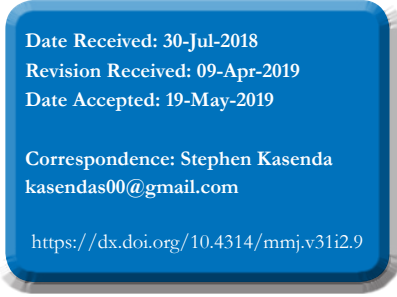

Wilms' tumour is the most common renal neoplasm in children with an incidence of 10 cases per 1 million children and a median age at diagnosis of 3.5 years. In Western countries its occurrence in adults is 0.2 cases per million people in western countries and carries a poorer prognosis. The co-existence of Adult Wilms' tumour and pregnancy is extremely rare with less than 20 cases published in the English literature. We present a case of a Malawian woman who had progressive high-risk metastatic Adult Wilms' tumour in pregnancy after nephrectomy, radiotherapy and two lines of chemotherapy.

Keywords: Africa, Antineoplastic Combined Chemotherapy Protocols, incidence, kidney, Kidney neoplasms, Malawi, pregnancy, Wilms' tumour

\section{Introduction}

The coexistence of pregnancy and malignancy is a rare phenomenon with an incidence rate of 1 in 1000 pregnancies in the developed world ${ }^{1-4}$. The incidence in Africa is thought to be lower than that of developed countries because women in developing countries get pregnant at younger ages ${ }^{5}$. Among the malignancies that have been recorded to co-exist with pregnancy, $70-80 \%$ of the cases were the following cancers: breast, cervical, lymphoma, ovarian, and melanoma ${ }^{2,6}$.

Queen Elizabeth Central Hospital (QECH) records indicate that $11(1.05 \%)$ of female cancer patients who presented between 1 January 2015 and 31 December 2017 were pregnant. Among these patients, haematological malignancies were the most common $(n=6)$ followed by breast carcinoma (2), Kaposi's sarcoma (1), Osteosarcoma (1) and Wilms' tumour (1).

Wilms' tumour has an incidence of 10 cases/million children with a median age of 3.5 years at the time of diagnosis ${ }^{7,8}$. It accounts for $6 \%$ of paediatric malignancies and is associated with a $42 \%$ five-year event free survival at $\mathrm{QECH}^{9,10}$. Adult Wilms' Tumour (AWT) has an estimated incidence of $<0.2$ cases/million individuals in western countries $(0.5 \%$ of all adult renal neoplasms $)^{11-13}$. Its incidence is associated with mutations in WT1, CTNNB1, IGF2 and WTX genes ${ }^{14}$. Adult Wilm's tumour has a worse prognosis due to lack of established treatment protocols, its highly aggressive course and metastatic potentia ${ }^{17,13}$. Adults also tend to have a lower drug toxicity threshold and advanced disease at the time of diagnosis ${ }^{7,13,15}$.

Adult Wilm's tumour diagnosis is based on the criteria developed by Kilton et. al which are: a primary renal neoplasm in the age group of $>15$ years with histological features of embryonic glomerulo-tubular structure with immature spindle or round cell stroma and no areas of tumour diagnostic of renal cell carcinoma ${ }^{11,13}$.

\section{Case Presentation}

In January 2016, a 23 year old HIV negative woman presented at the QECH oncology clinic with a diagnosis of International Society of Paediatric Oncology stage IV High risk AWT made at Nottingham University Hospital (August 2014). At the time of diagnosis, she had a primary tumour in the left kidney, a solitary liver metastasis and multiple right lung metastases. During her treatment course in Nottingham, she had actinomycin, vincristine and doxorubicin induction chemotherapy (August-October 2014) with partial response. This was changed to high-risk protocol: cyclophosphamide/ doxorubicin alternating with etoposide/carboplatin (November 2014).

In January 2015, she had a resection of the primary tumour and liver metastasis. Radiotherapy to the left flank to a dose of 24 Grays and the whole right lung to a dose of 18 Grays followed (February 2015) and Doxorubicin was omitted during her radiotherapy. In September 2015 upon completion of chemotherapy, CT scan confirmed partial response of her lung metastases and no evidence of disease below the diaphragm. Resection of the lung lesions was not feasible due to their multiplicity. Therefore close monitoring was opted for. No other significant medical history was available. At the time of presentation at $\mathrm{QECH}$, socio-economic circumstances had limited her oncology care options to QECH. She also had no radiological evidence of disease progression, an Eastern Cooperative Oncology Group performance status (ECOG) score of 1 (ambulatory but incapable of strenuous work) and normal laboratory results. After 15 months on follow-up, she developed intermittent dyspnoea and right-sided chest pain. Chest radiograph 
revealed right lung fibrotic changes in the upper lobe with collapse of the middle and lower lung zone (Figure 2). A coincidental discovery of pregnancy (G2P1) with an intrauterine singleton pregnancy of 15 weeks gestation age by ultrasound scan was also made. After non-directive counselling she opted for close follow-up.

A foetal anomaly scan at 22 weeks gestation revealed no anomalies and subsequent growth scans were normal. She developed lower back pain and had elevated serum calcium (3.2mmol/L, normal range: $2.0-2.5 \mathrm{mmol} / \mathrm{L})$, Alkaline phosphatase $(128.2 \mathrm{U} / \mathrm{L} ; 0-126 \mathrm{U} / \mathrm{L})$ and lactate dehydrogenase (754.3 U/L; 0-248 U/L). MRI showed: a large left pleural effusion with multiple heterogeneous masses within the left lung, large mediastinal lymph nodes, and a large heterogeneous right kidney mass (Figures $3 \& 4$ ). he was started on Zoledronate $4 \mathrm{mg}$ IV and had a miscarriage two days later at 25 weeks gestation. She presented again 10 days later and was started on chemotherapy while having an ECOG score of 3 (bedbound for $>50 \%$ of waking hours), cachexia and pitting oedema. Throughout the follow-up period she maintained normal renal function and had no thromboembolic events. She died of lung failure two days after starting ifosfamide, carboplatin and etoposide.

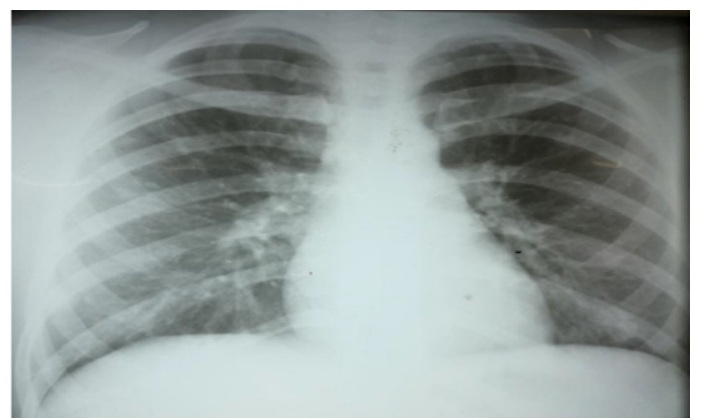

Figure 1: X-ray image from January 2016

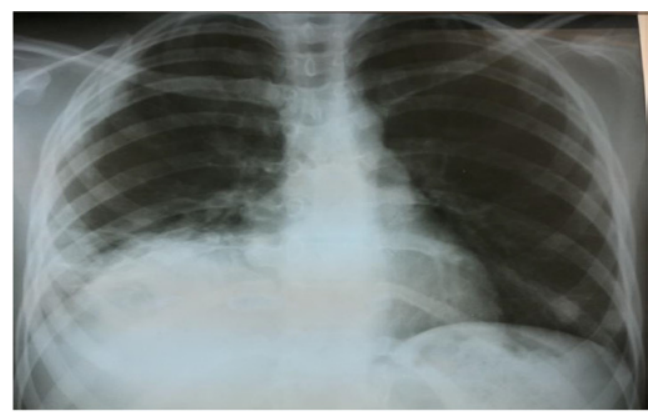

Figure 2: X-ray image from March 2017

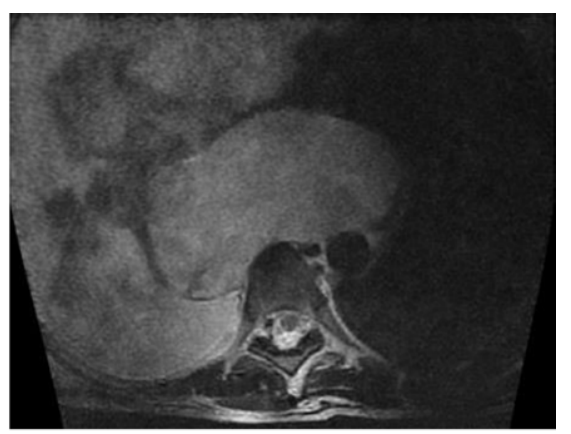

Figure 3: Axial T2 weighted MRI sequence

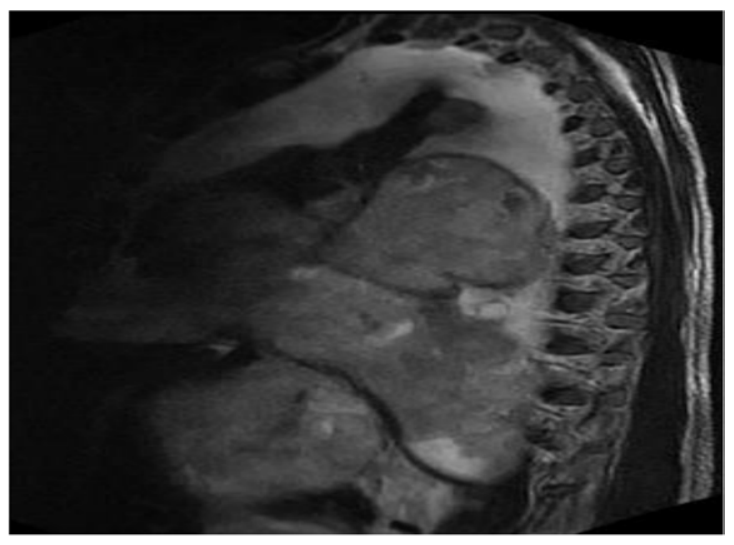

Figure 4: Sagittal T2 weighted MRI sequence

\section{Discussion}

We accessed 10 reports on the coexistence of AWT with pregnancy in published English literature ${ }^{16-26}$. It is our postulation that progressive tumours precipitated the miscarriage and this could have potentially been mitigated by early onset chemotherapy. Previous exposure to heavy treatment of her metastatic disease and declining performance status however portended a poor prognosis ${ }^{27}$.

Our patient also experienced the co-existence of several factors associated with the development of psychological distress namely: (I) young age, (II) advanced and recurrent disease, (III) declining functional status, (IV) previous experience with cancer therapy, (V) presence of socioeconomic challenges and (VI) the maternal-foetal beneficence conflict resulting from cancer in pregnancy ${ }^{28-34}$. The presence of psychological distress has been associated with disease progression or relapse, reduced quality-oflife, impaired social relationships, increased risk of suicide, longer rehabilitation time, poor adherence to treatment and shorter survival ${ }^{30,35-37}$. It is for this reason that distress and psychological support have been designated as a sixth vital sign and human right in cancer patients respectively ${ }^{38,39}$.

Management of pregnancy-associated cancer is difficult due to lack of robust evidence, paucity of established treatment guidelines and complexity of considerations including beneficence obligations of clinicians to the mother and foetus ${ }^{28,40-43}$. Care for these patients in resource limited settings is also challenged due to availability of: (I)access to care, (II)diagnostic services, (III) treatment and (IV) personnel for interdisciplinary care ${ }^{10,39,44-47}$. Thus patients are likely to be diagnosed with advanced disease and experience delays in starting treatment; with consequential poor survival.

These challenges reflect resource distribution challenges which require long term investment in health care. The maternal-foetal ethical conflict highlights the importance of patient education on fertility issues and provision of contraception.

\section{Consent}

Written informed consent was obtained from the patient for the publication of this case report and accompanying images.

\section{References}

1. Salani R, Billingsley CC, Crafton SM. Cancer and pregnancy: an overview for obstetricians and gynecologists. Am J Obstet Gynecol . 2014 Feb 27;211(1):7-14. Doi: 10.1016/j.ajog.2013.12.002 
2. Zagouri F, Dimitrakakis C, Marinopoulos S, Tsigginou A, Dimopoulos M-A. Cancer in pregnancy: disentangling treatment modalities. ESMO Open . 2016 Feb 26;1(3). Doi: 10.1136/esmoopen-2015-000016

3. Mitrou S, Zarkavelis G, Fotopoulos G, Petrakis D, Pavlidis N. A mini review on pregnant mothers with cancer: A paradoxical coexistence. J Adv Res . 2016 Mar 13;7(4):559-63. Doi: 10.1016/j.jare.2016.01.004

4. Esposito S, Tenconi R, Preti V, Groppali E, Principi N. Chemotherapy against cancer during pregnancy. Medicine (Baltimore) . 2016 Mar 13;95(38). Doi:10.1097/MD.0000000000004899

5. Pentheroudakis G, Pavlidis N. Cancer and pregnancy: poena magna, not anymore. Eur J Cancer (Oxford, Engl 1990) . 2006;42(2):126-40. Doi: $10.1016 /$ j.ejca.2005.10.014

6. Weisz B, Schiff E, Lishner M. Cancer in pregnancy: maternal and fetal implications. Hum Reprod Update . 2001;7(4):384-93. Doi: 10.1093/humupd/7.4.384

7. Ercolak V, Kara İO, Duman BB, Günaldı M, Afşar ÇU, Erdoğan Ş, et al. A case report of adult Wilms' tumour. Contemp Oncol Onkol. 2014;1-4. Doi: 10.5114/wo.2014.40616

8. Szychot E, Apps J, Pritchard-Jones K. Wilms' tumor: biology, diagnosis and treatment. Transl Pediatr . 2014 Mar 13;3(1):12-24. Doi: 10.3978/j.issn.2224-4336.2014.01.09

9. Israels T, Pidini D, Borgstein E, Bailey S, Tump C, Chagaluka $\mathrm{G}$, et al. Survival of children with a Wilms tumor in Blantyre, Malawi. Pediatr Hematol Oncol . 2018 Mar 13;35(3):196-202. Doi: 10.1080/08880018.2018.1498564

10. Wilde J., Lameris W, van Hasselt E, Molyneux E, Heij H, Borgstein E. Challenges and outcome of Wilms' tumour management in a resourceconstrained setting. African J Paediatr Surg . 2010 Mar 13;7(3):159. Doi: 10.4103/0189-6725.70416

11. Al-Hussain T, Ali A, Akhtar M. Wilms tumor: an update. Adv Anat Pathol . 2014;21(3):166-73. Doi: 10.1097/PAP.0000000000000017

12. Ali AN, Diaz R, Shu H-K, Paulino AC, Esiashvili N. A Surveillance, Epidemiology and End Results (SEER) program comparison of adult and pediatric Wilms' tumor. Cancer . 2012;118(9):2541-51. Doi: $10.1002 /$ cncr. 26554

13. Ali EM, Elnashar AT. Adult Wilms' tumor: review of literature. J Oncol Pharm Pract Off Publ Int Soc Oncol Pharm Pract . 2012;18(1):14851. Doi: $10.1177 / 1078155210396264$

14. Md Zin R, Murch A, Charles A. Pathology, genetics and cytogenetics of Wilms' tumour. Pathology . 2011;43(4):302-12. Doi: 10.1097/ PAT.0b013e3283463575

15. Geethamani V, Kusuma V, Gowda KMS, Saini ML. Adult Wilms' tumour: a case report with review of literature. Diagn Pathol . $2006 \mathrm{Mar}$ 13;1:46. Doi: 10.1186/1746-1596-1-46

16. Wynn T, Ruymann FB, King DR, Luquette M. Second pregnancyassociated Wilms tumor 16 years after the first one. Med Pediatr Oncol 2003;40(2):120-2. Doi: 10.1002/mpo.10086

17. Vijayasarathy K, Martin PJM, Mavalavan D. An Uneventful Pregnancy and Delivery in a Metastatic Adult Wilms' Tumor-A Rare Case Report. MOJ Clin Med Case Reports . 2017 Mar 13;7(4). Doi: 10.15406/mojcr.2017.07.00211

18. Sarangi DS, Sarkar DU, Chakrabarti DS. A Rare Case of Adult Wilms' Tumour in a Pregnant Female. Sch J Med Case Reports . 2016 Mar 13;4(6):385-7. Doi: 10.21276/sjmcr.2016.4.6.7

19. Rodrigues FA, Ribeiro EC, Maroccolo Filho R, Silva EA, Diaz FAF. Adult Wilms tumor during gestational period. Urology . 2009;73(4):929. e1-2. Doi: 10.1016/j.urology.2008.05.017

20. Rehman J, Chughtai B, Guru K, Khan SA, Adler HL, Miller F. Wilm's tumor during pregnancy: report of laparoscopic removal and review of literature. Can J Urol . 2008;15(4):4180-3.

21. Maurer T, Zorn C, Klein E, Weirich G, Beer AJ, Gschwend JE, et al. Multimodal tumor therapy in a 31-year-old pregnant woman with Wilms tumor. Urol Int . 2009;83(3):364-7. Doi: 10.1159/000241685

22. Khan IA, Basu S, Khan D, Choudhary A, Khan S. Wilms' Tumour in an Adult Female Complicating Pregnancy: A Case Report. J Clin Diagnostic Res . 2018 Mar 13; Doi: 10.7860/JCDR/2018/32860.11658

23. Corapcioglu F, Dillioğlugil Ö, Sarper N, Akansel G, Çalışkan M, Arısoy AE. Spinal cord compression and lung metastasis of Wilms' tumor in a pregnant adolescent. Urology . 2004 Mar 13;64(4):807-10. Doi: 10.1016/j.urology.2004.05.032

24. Byrd LM, Malay HK, Vause S. Management of a Wilms' tumour, in a Jehovah's Witness, 30+ weeks pregnant. Eur J Obstet Gynecol Reprod Biol . 2006;126(1):129-31. Doi: 10.1016/j.ejogrb.2005.10.035

25. Bozeman G, Bissada NK, Abboud MR, Laver J. Adult Wilms' tumor: prognostic and management considerations. Urology 1995;45(6):1055-8.Doi: 10.1016/S0090-4295(99)80132-0

26. Alexander VM, Meisel J, O'Brien S, Khanna N. Wilms' tumor of the ovary. Gynecol Oncol Reports . 2017 Mar 13;19:18-21. Doi: 10.1016/j.gore.2016.12.004

27. West H (Jack), Jin JO. Performance Status in Patients With Cancer. JAMA Oncol . 2015 Mar 13;1(7):998. Doi: 10.1001/ jamaoncol.2015.3113

28. Ives A, Musiello T, Saunders C. Psychological and Psychosocial Care of a Pregnant Woman with Cancer. In: Azim Jr HA, editor. Managing Cancer during Pregnancy. Cham: Springer International Publishing; 2016. p. 79-87. Doi: 10.1007/978-3-319-28800-0_7

29. Ferrari F, Faccio F, Peccatori F, Pravettoni G. Psychological issues and construction of the mother-child relationship in women with cancer during pregnancy: a perspective on current and future directions. BMC Psychol . 2018 Feb 26;6. Doi: 10.1186/s40359-018-0224-5

30. Caruso R, Nanni MG, Riba MB, Sabato S, Grassi L. The burden of psychosocial morbidity related to cancer: patient and family issues. Int Rev Psychiatry . 2017 Mar 13;29(5):389-402. Doi: 10.1080/09540261.2017.1288090

31. Henry M, Huang LN, Sproule BJ, Cardonick EH. The psychological impact of a cancer diagnosed during pregnancy: determinants of longterm distress. Psychooncology . 2012 Feb 27;21(4):444-50. Doi: 10.1002/pon. 1926

32. Mertz BG, Bistrup PE, Johansen C, Dalton SO, Deltour I, Kehlet $\mathrm{H}$, et al. Psychological distress among women with newly diagnosed breast cancer. Eur J Oncol Nurs . 2012 Mar 13;16(4):439-43. Doi: 10.1016/j.ejon.2011.10.001

33. Okediji PT, Salako O, Fatiregun OO. Pattern and Predictors of Unmet Supportive Care Needs in Cancer Patients. Cureus . 2017 Mar 13; Doi: $10.7759 /$ cureus. 1234

34. Harrison P. Psychosocial Impact of a Cancer Diagnosis During Pregnancy. Nurs Womens Health . 2013 Mar 13;17(5):437-42. Doi: 10.1111/1751-486X.12067

35. Chan CMH, Wan Ahmad WA, MD Yusof M, Ho G-F, Krupat E. Effects of depression and anxiety on mortality in a mixed cancer group: a longitudinal approach using standardised diagnostic interviews: Depression and anxiety on cancer mortality. Psychooncology . 2015 Mar 13;24(6):718-25. Doi: 10.1002/pon.3714

36. Travado L, Breitbart W, Grassi L, Fujisawa D, Patenaude A, Baider L, et al. 2015 President's Plenary International Psycho-oncology Society: psychosocial care as a human rights issue-challenges and opportunities: COMMENTARY. Psychooncology . 2017 Mar 13;26(4):563-9. Doi: 10.1002/pon.4209

37. Castelli L, Castelnuovo G, Torta R. Editorial: PsychOncology: clinical psychology for cancer patients - Cancer: the key role of clinical psychology. Front Psychol . 2015 Feb 26;6. Doi: 10.3389/ fpsyg.2015.00947

38. Watson M, Bultz BD. Distress, the 6th vital sign in cancer care: 
Caring for patients' emotional needs: what does this mean and what helps? Psycho-Oncologie . 2010 Mar 13;4(3):159-63. Doi: 10.1007/ s11839-010-0269-z

39. Travado L, Bultz BD, Ullrich A, Asuzu CC, Turner J, Grassi L, et al. 2016 President's Plenary International Psycho-Oncology Society: challenges and opportunities for growing and developing psychosocial oncology programmes worldwide. Psychooncology. 2017 Mar 13;26(9):1231-8. Doi: 10.1002/pon.4471

40. de Haan J, Verheecke M, Van Calsteren K, Van Calster B, Shmakov RG, Mhallem Gziri M, et al. Oncological management and obstetric and neonatal outcomes for women diagnosed with cancer during pregnancy: a 20-year international cohort study of 1170 patients. Lancet Oncol . 2018 Mar 13;19(3):337-46. Doi: 10.1016/S1470-2045(18)30059-7

41. Pereg D, Koren G, Lishner M. Cancer in pregnancy: Gaps, challenges and solutions. Cancer Treat Rev . 2008 Mar 13;34(4):30212. Doi: $10.1016 /$ j.ctrv.2008.01.002

42. Van Calsteren K, Amant F. Cancer during pregnancy. Acta Obstet Gynecol Scand . 2014 Mar 13;93(5):443-6. Doi: 10.1111/aogs.12380
43. Chervenak FA, McCullough LB, Knapp RC, Caputo TA, Barber HRK. A clinically comprehensive ethical framework for offering and recommending cancer treatment before and during pregnancy. Cancer . 2004 Mar 13;100(2):215-22. Doi: 10.1002/cncr.11564

44. Makwero MT. Delivery of primary health care in Malawi. African J Prim Heal Care Fam Med. 2018 Feb 22;10(1). Doi: 10.4102/phcfm. v10i1.1799

45. Köhler C, Marnitz S. Cancer in pregnancy: evidence, or still empiricism? Lancet Oncol . 2018 Feb 22;19(3):272-4. Doi: 10.1016/ S1470-2045(18)30058-5

46. Lee Y, Roberts C, Dobbins T, Stavrou E, Black K, Morris J, et al. Incidence and outcomes of pregnancy-associated cancer in Australia, 1994-2008: a population-based linkage study: Pregnancy-associated cancer: incidence and outcomes. BJOG An Int J Obstet Gynaecol . 2012 Mar 13;119(13):1572-82. Doi: 10.1111/j.1471-0528.2012.03475.x 